\title{
Feasibility of Bariatric Surgery as a Strategy for Secondary Prevention in Cardiovascular Disease: A Report from the Swedish Obese Subjects Trial
}

\author{
Lotta Delling, ${ }^{1}$ Kristjan Karason, ${ }^{1}$ Torsten Olbers, ${ }^{2}$ David Sjöström, ${ }^{1}$ Björn Wahlstrand, ${ }^{1}$ \\ Björn Carlsson, ${ }^{1}$ Lena Carlsson, ${ }^{1}$ Kristina Narbro, ${ }^{1,3}$ Jan Karlsson, ${ }^{1}$ Carl Johan Behre, ${ }^{1}$ \\ Lars Sjöström, ${ }^{1}$ and Kaj Stenlöf ${ }^{1}$
}

${ }^{1}$ Department of Medicine, The Sahlgrenska Academy, University of Gothenburg, Gröna Stråket 8, 41345 Göteborg, Sweden

${ }^{2}$ Department of Surgery, The Sahlgrenska Academy, University of Gothenburg, SE-413 45 Göteborg, Sweden

${ }^{3}$ Department of Health Care, Regional Secretariat, Västra Götaland Region, SE-405 44 Göteborg, Sweden

Correspondence should be addressed to Lotta Delling, lotta.delling@vgregion.se

Received 12 March 2010; Accepted 8 June 2010

Academic Editor: Marco Anselmino

Copyright (C) 2010 Lotta Delling et al. This is an open access article distributed under the Creative Commons Attribution License, which permits unrestricted use, distribution, and reproduction in any medium, provided the original work is properly cited.

\begin{abstract}
Aims. Evaluation of bariatric surgery as secondary prevention in obese patients with ischemic heart disease (IHD). Methods. Analysis of data from 4047 subjects in the Swedish Obese Subjects (SOSs) study. Thirty-five patients with IHD are treated with bariatric surgery $(n=21)$ or conventional treatment $(n=14)$. Mean follow-up is 10.8 years. Results. Bariatric surgery resulted in sustained weight loss during the study period. After 2 years, the surgery group displayed significant reductions in cardiovascular risk factors, relief from cardiorespiratory symptoms, increments in physical activity, and improved quality of life. After 10 years, recovery from hypertension, diabetes, physical inactivity, and depression was still more common in the surgery group. There were no signs of increased cardiovascular morbidity or mortality in the surgery group. Conclusion. Bariatric surgery appears to be a safe and feasible treatment to achieve long-term weight loss and improvement in cardiovascular risk factors, symptoms, and quality of life in obese subjects with IHD.
\end{abstract}

\section{Introduction}

Obesity, together with associated clustering of cardiovascular risk factors, is a strong promoter for cardiovascular disease morbidity and mortality $[1,2]$. Weight control is considered a cornerstone in primary prevention aimed at reducing the overall incidence of cardiovascular disease. Obesity is also frequently targeted in secondary preventive programs intended to improve outcome in patients with already established cardiovascular disease $[3,4]$. One major problem with standard strategies is that weight loss is difficult to achieve with conventional methods and the results are often temporary.

Bariatric surgery has emerged as an effective treatment option to obtain large and sustained weight loss in obese subjects [5]. Surgically induced weight loss has been shown to improve or prevent many of the obesityrelated cardiovascular risk factors including hypertension, dyslipidemia, diabetes, and obstructive sleep apnea $[1,2,5-$ 9]. In addition, surgical intervention has been shown to restrain the progression rate $[10,11]$ and in some cases even reverse [12] the development of early atherosclerosis. More recently, bariatric surgery has been demonstrated to reduce overall and cardiovascular mortality when applied as primary preventive strategy in morbid obesity [6].

Despite these encouraging findings, the use of bariatric surgery in patients with established cardiovascular disease has been limited. One probable explanation is the concern about increased perioperative risk in this patient population, but another reason could be the growing scepticism towards weight control as a secondary preventive measure. Uncertainty has arisen since several large epidemiological 
studies have revealed an inverse relationship between BMI and outcome in patients with ischemic heart disease [13]. An apparent "protective quality" of obesity has been demonstrated in patients with acute coronary syndromes and those undergoing coronary artery bypass grafting [14-16]. On the other hand, it has been pointed out that the so-called "obesity paradox" may just as well be related to adverse prognosis in patients with disease-related cachexia. In any case, the controversy remains and calls for controlled intervention studies.

Bearing this in mind, the present study was aimed to evaluate the safety and feasibility of bariatric surgery as a preventive measure in obese subjects with ischemic heart disease. This was performed by analysing data from the Swedish Obese Subjects (SOS) controlled surgical intervention trial.

\section{Methods}

2.1. The SOS Study. Briefly, obese patients (BMI $\geq 38 \mathrm{~kg} / \mathrm{m}^{2}$ for women and BMI $\geq 34 \mathrm{~kg} / \mathrm{m}^{2}$ for men) between 37 and 60 years of age were assigned to either bariatric surgery or conventional obesity treatment as described in earlier studies [6]. Surgical intervention consisted of gastric banding, vertical banded gastroplasty, or gastric bypass, whereas control treatment involved conventional life style recommendations. Exclusion criteria were minimal and allowed for a coronary event outside 6 months of inclusion. The study complied with the Declaration of Helsinki and was approved by the regional boards for ethical approval.

2.2. Present Study Group. In the total SOS study cohort of 4047 subjects, 62 patients reported a history of myocardial infarction at the time of screening. After evaluating ECG recordings and hospital records, a prior coronary event defined as myocardial infarction, unstable angina, or prior revascularization, could be verified in 37 of these subjects. Two patients were excluded from the present report due to early drop out, resulting in a final study group of 35 subjects (11 women and 24 men). Of these subjects, 21 underwent bariatric surgery and 14 received conventional treatment. Patients were evaluated at inclusion and again after 2 and 10 years. The average follow-up period was 10.8 years (range 6.3 - 17.4 years). One subject declined two-year evaluation but participated in the 10-year follow-up. Twenty-one patients completed the 10-year follow-up ( 7 patients had died, 3 patients had not attained 10 years of follow-up, 3 patients had withdrawn their consent, and 1 patient had emigrated).

2.3. Clinical and Laboratory Assessments. At each visit measurements of body weight and height were obtained and blood pressure recorded. Blood samples were drawn in the morning after 10-12 hours of fasting. Blood glucose and serum lipids were analysed by enzymatic techniques (accredited according to European Norm 45001).

2.4. Cardiovascular Risk Factors. Hypertension was defined as systolic blood pressure $\geq 140 \mathrm{mmHg}$ or diastolic blood

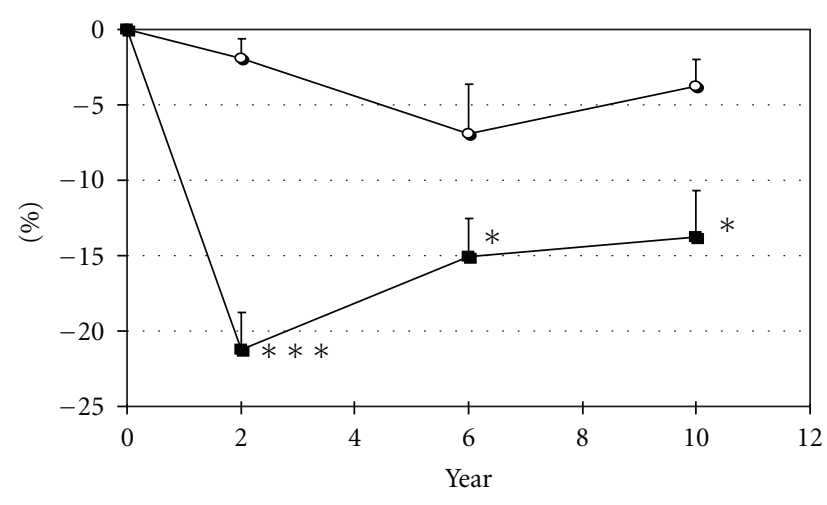

Figure 1: Mean weight change (\%) at 2, 6, and 10 years of followup in the surgery and control groups. Filled squares: surgery; Open circles: controls. ${ }^{* * *} P<.001,{ }^{*} P<.05$.

pressure $\geq 90 \mathrm{mmHg}$ or treatment with antihypertensive medication. Dyslipidemia was classified as total cholesterol $\geq 5.2 \mathrm{mmol} / \mathrm{L}$ or triglycerides $\geq 2.8 \mathrm{mmol} / \mathrm{L}$ or current lipid lowering medication. The criteria for diabetes were fasting glucose $\geq 6.1 \mathrm{mmol} / \mathrm{L}$ or treatment with insulin or oral hypoglycemic agents.

2.5. Cardiorespiratory Symptoms, Physical Activity, and Quality of Life. Patients completed a questionnaire at inclusion and again after 2 and 10 years of follow-up. They were asked about the occurrence of chest pain and breathlessness and whether a family member or other person had observed pauses in breathing during sleep. Subjects were also asked to grade their level of physical activity during working and leisure time and health related quality of life (HRQOL). The HRQOL evaluation included questions regarding current health perception, social interaction, obesity-related problems, overall mood, anxiety, and depression.

2.6. Adverse Events. Information regarding gastrointestinal and cardiovascular adverse events was obtained from selfadministered questionnaires and verified by cross-checking hospital records. A cardiovascular event was defined as hospitalisation or death due to cardiovascular disease. Information about perioperative complications was obtained from surgical trial reports and discharge reports filled in by the surgeon. Information on cause of death was acquired from registries provided by the Swedish National Board of Health Welfare.

2.7. Statistical Methods. Data are summarised as means $( \pm \mathrm{SD})$ for continuous variables and percentages for categorical data. Differences between groups and changes from baseline were evaluated with paired ttests for continuous variables, with Fisher's exact test or McNemar's test for categorical variables, and with Pitman's nonparametrical test for quality of life data. Data on gastrointestinal and cardiovascular adverse events, as well as mortality, are presented in a descriptive manner. 
TABLe 1: Anthropometrics and prevalence of cardiovascular risk factors (\%) in the surgery and control groups at baseline and changes in prevalence after 2 and 10 years of follow-up. Only the patients applicable for the certain timepoint are included in the statistical calculations.

\begin{tabular}{|c|c|c|c|}
\hline & Baseline & $\begin{array}{l}\text { Change at 2-year } \\
\text { follow-up }\end{array}$ & $\begin{array}{l}\text { Change at 10-year } \\
\text { follow-up }\end{array}$ \\
\hline & Surgery $n=21$ & Surgery, $n=21$ & Surgery, $n=13$ \\
\hline & Control $n=14$ & Control, $n=13$ & Control, $n=8$ \\
\hline \multicolumn{4}{|l|}{ Weight, kg } \\
\hline Surgery & $122.8 \pm 15$ & $-26.3 \pm 14.7^{* * *}$ & $-17.3 \pm 13.1^{*}$ \\
\hline Control & $115.3 \pm 18$ & $-2.3 \pm 5.2$ & $-4.3 \pm 5.2$ \\
\hline \multicolumn{4}{|l|}{ BMI, $\mathrm{kg} / \mathrm{m}^{2}$} \\
\hline Surgery & $40.6 \pm 4.3$ & $-8.6 \pm 4.8^{* * *}$ & $-5.6 \pm 4.2^{*}$ \\
\hline Control & $38.0 \pm 4.5$ & $-0.8 \pm 1.8$ & $-1.5 \pm 2.0$ \\
\hline \multicolumn{4}{|c|}{ Waist circumference, $\mathrm{cm}$} \\
\hline Surgery & $128.3 \pm 8.3$ & $-21.2 \pm 12.5$ & $-12.9 \pm 12.2$ \\
\hline Control & $123.5 \pm 9.1$ & $-12.9 \pm 12.2$ & $-3.7 \pm 6.0$ \\
\hline \multicolumn{4}{|c|}{ Current smoker \% } \\
\hline Surgery & 52.4 & $-20.0^{*}$ & -18.2 \\
\hline Control & 50.0 & -14.8 & -22.2 \\
\hline \multicolumn{4}{|c|}{ Hypertension \% } \\
\hline Surgery & 57.1 & $-15.0^{* * *}$ & $-23.1^{*}$ \\
\hline Control & 53.8 & 21.2 & 0 \\
\hline \multicolumn{4}{|c|}{ Dyslipidemia \% } \\
\hline Surgery & 95.2 & $-28.5^{* * *}$ & -69.2 \\
\hline Control & 92.9 & 0 & -22.2 \\
\hline \multicolumn{4}{|l|}{ Diabetes \% } \\
\hline Surgery & 52.4 & $-14.3^{* * *}$ & $-7.7^{* * *}$ \\
\hline Control & 50.0 & 0 & 11.1 \\
\hline
\end{tabular}

$P$-value denotes differences in effects of treatment between the two groups from baseline to 2 and 10 years of follow-up. ${ }^{*} P<.05,{ }^{* * *} P<.001$.

\section{Results}

3.1. Demographics. At baseline, the surgery group $(n=$ $21)$ and control group $(n=14)$ were comparable with respect to age $(50.9 \pm 5.7$ versus $53.2 \pm 4.9$ years $)$, gender distribution ( $33 \%$ versus $40 \%$ females), and body weight $(122 \pm 15$ versus $115 \pm 18 \mathrm{~kg})$.

Bariatric surgery resulted in sustained weight loss after 2 and 10 years (surgery: $-21.2 \%$ after 2 years and $-13.8 \%$ after 10 years, controls: $-2.4 \%$ after 2 years and $-3.8 \%$ after 10 years, $P<.001$ ) (Figure 1). Changes in body weight, BMI, and waist circumference are shown in Table 1.

3.2. Cardiovascular Risk Factors. At baseline, the prevalence of hypertension, dyslipidemia, and diabetes was similar in the two study groups. After 2 years, the surgery group displayed significant improvements in all of these cardiovascular risk factors as compared to control subjects. After 10 years, recovery from hypertension and diabetes was still more prevalent among surgically treated patients (Table 1).

3.3. Cardiorespiratory Symptoms and Physical Activity. At baseline, the prevalence of sleep disordered breathing was similar in the two study groups, whereas the surgery group reported lower frequencies of chest pain, breathlessness, and a higher degree of physical inactivity. After two years of follow-up, surgical patients displayed significant improvements in all 4 conditions, as compared with control subjects. After 10 years, a reversal of physical inactivity was still more common in the surgery group (Table 2 ).

3.4. Health-Related Quality of Life. HRQOL was similar in both study groups at baseline, except for obesity-related problems, which were reported more often in the surgery group. After 2 years, the surgery group displayed diminutions in obesity-related problems and improvements in social interaction and depression score, as compared with controls. After 10 years, recovery from depression and obesity-related problems was still more frequent in the surgery group (Table 3).

3.5. Adverse Events. In patients who underwent bariatric surgery there were no postoperative deaths. One patient bled $1300 \mathrm{~mL}$ during surgery. Otherwise there were no perioperative complications reported. Frequent adverse events included nausea and/or abdominal pain, which lead to unscheduled gastroscopy in 12 patients (57\%). Serious adverse events, requiring surgical or endoscopic treatment, 
TABLE 2: Chest pain, breathlessness sleep apnea, and physical activity (\%) in the surgery and control groups at baseline and changes in prevalence after 2 and 10 years of follow-up. Only the patients applicable for the certain timepoint are included in the statistical calculations.

\begin{tabular}{|c|c|c|c|}
\hline & Baseline & $\begin{array}{l}\text { Change at 2-year } \\
\text { follow-up }\end{array}$ & $\begin{array}{c}\text { Change at } 10 \text {-year } \\
\text { follow-up }\end{array}$ \\
\hline & Surgery $n=21$ & Surgery, $n=21$ & Surgery, $n=13$ \\
\hline & Control $n=14$ & Control, $n=13$ & Control, $n=8$ \\
\hline \multicolumn{4}{|c|}{ Chest pain \% } \\
\hline Surgery & 38.1 & $-18.1^{* * *}$ & -36.4 \\
\hline Control & 84.6 & -7.7 & -33.3 \\
\hline \multicolumn{4}{|c|}{ Breathlessness \% } \\
\hline Surgery & 61.9 & $-51.9^{* *}$ & -45.4 \\
\hline Control & 84.6 & 23.1 & 25 \\
\hline \multicolumn{4}{|c|}{ Sleep apnea \% } \\
\hline Surgery & 52.4 & $-42.1^{* * *}$ & -54.5 \\
\hline Control & 53.8 & 0 & -66.7 \\
\hline \multicolumn{4}{|c|}{ Physical inactivity \% } \\
\hline Surgery & 47.6 & $-12.6^{* * *}$ & $-18.2^{* *}$ \\
\hline Control & 30.8 & 23.0 & 11.1 \\
\hline
\end{tabular}

TABLE 3: Health related quality of life in surgery and control groups at baseline and changes in prevalence after 2 and 10 years of follow-up. Only the patients applicable for the certain timepoint are included in the statistical calculations.

\begin{tabular}{|c|c|c|c|}
\hline & Baseline & $\begin{array}{l}\text { Change at 2-year } \\
\text { follow-up }\end{array}$ & $\begin{array}{c}\text { Change at } 10 \text {-year } \\
\text { follow-up }\end{array}$ \\
\hline & Surgery, $n=21$ & Surgery, $n=21$ & Surgery, $n=13$ \\
\hline & Control, $n=14$ & Control, $n=13$ & Control, $n=8$ \\
\hline \multicolumn{4}{|c|}{ Current health perceptions } \\
\hline Surgery & $41.3 \pm 19.8$ & $21.8 \pm 30.3$ & $-0.8 \pm 14.5$ \\
\hline Control & $35.1 \pm 24.2$ & $6.6 \pm 16.2$ & $6.8 \pm 29.3$ \\
\hline \multicolumn{4}{|c|}{ Social interaction } \\
\hline Surgery & $15.5 \pm 15.6$ & $-9.9 \pm 12.6^{*}$ & $-3.4 \pm 8.9$ \\
\hline Control & $15.8 \pm 11.1$ & $0.4 \pm 9.9$ & $-9.7 \pm 12.0$ \\
\hline \multicolumn{4}{|c|}{ Obesity-related Problems scale } \\
\hline Surgery & $48.4 \pm 31.3$ & $-35.1 \pm 26.5^{* * *}$ & $-31.0 \pm 26.7^{* *}$ \\
\hline Control & $28.3 \pm 27.7$ & $8.7 \pm 19.6$ & $-0.8 \pm 14.6$ \\
\hline \multicolumn{4}{|c|}{ Overall Mood } \\
\hline Surgery & $2.85 \pm 0.52$ & $0.23 \pm 0.41$ & $0.09 \pm 0.34$ \\
\hline Control & $2.79 \pm 0.63$ & $-0.01 \pm 0.55$ & $0.18 \pm 0.32$ \\
\hline \multicolumn{4}{|l|}{ Anxiety } \\
\hline Surgery & $6.5 \pm 4.4$ & $-1.7 \pm 3.5$ & $-1.2 \pm 2.8$ \\
\hline Control & $7.5 \pm 4.8$ & $-1.0 \pm 2.7$ & $-2.4 \pm 4.2$ \\
\hline \multicolumn{4}{|l|}{ Depression } \\
\hline Surgery & $5.2 \pm 2.8$ & $-1.9 \pm 2.7^{*}$ & $-0.7 \pm 2.6^{*}$ \\
\hline Control & $5.1 \pm 2.7$ & $0.5 \pm 2.2$ & $0.1 \pm 2.8$ \\
\hline
\end{tabular}

$P$-value denotes differences in effects of treatment between the two groups from baseline to 2 and 10 years of follow-up. ${ }^{*} P<.05,{ }^{* *} P<.01,{ }^{* * *} P<.001$. Current health perceptions: scale range 0-100; high scores represent well-being.

Social interaction: scale range and obesity-related problems scale 0-100; high scores indicate dysfunction.

Overall mood: scale range 1-4; high scores represent well-being.

Anxiety and depression: scale range 0-21; high scores represent symptoms. 
occurred in 3 patients (14\%) and consisted of pouch stenosis (1), pouch dilatation (1), and incisional hernia (1). No significant differences were observed between the surgery and control groups with respect to cardiovascular event rates, including myocardial infarction ( $42.9 \%$ versus $38.5 \%$ ) coronary revascularisation ( $47.6 \%$ versus $53.8 \%$ ) and total cardiovascular events (61.9\% versus $69.2 \%)$. Mean time to first event was 5.7 years in the surgery group and 5.5 years in the control group. During the follow-up period 6 patients $(29 \%)$ in the surgery group died, as compared with 5 patients $(38.5 \%)$ in the control group. The most common cause of death was cardiovascular (66.7\% versus $80 \%)$.

\section{Discussion}

The effect that obesity and weight loss have on secondary outcomes in ischemic heart disease remains unclear. Contrary to intuition, many studies report a protective effect of obesity on prognosis in IHD populations [13]. This "obesity paradox" has been described for acute coronary syndromes [17, 18], percutaneous coronary intervention $[14,16]$, and coronary artery bypass grafting [15]. In view of these findings, the present recommendations of weight control in patients with coronary heart disease have been questioned.

Even though, in small cohorts, we and others $[2,19]$ now provide data indicating that bariatric surgery can be a safe method to attain sustained weight loss also for obese subjects with established IHD, among patients treated with surgery there were no signs of increased short-term or long-term cardiovascular morbidity or mortality. Postoperative complications were comparable with those previously reported in obese patients free from cardiovascular disease.

The beneficial effects of bariatric surgery in the present study were in line with those previously observed $[6,8,20$, $21]$. After two years, surgically induced weight loss was associated with favourable effects on multiple cardiovascular risk factors, including abdominal obesity, hypertension, diabetes, and dyslipidemia. Patients also experienced a significant relief from symptoms of chest pain and breathlessness and reduction in sleep-disordered breathing. Physical activity during leisure time increased and several aspects of quality of life improved. After 10 years, recovery from hypertension, diabetes, physical inactivity, and depression was still more common in treated patients.

In view of the findings in the present study, previous concerns about increased perioperative risk associated with bariatric surgery appear to be unwarranted. Further, the widespread effects of surgical obesity treatment on symptoms and risk factors make it an attractive alternative in attaining secondary prevention in patients with ischemic heart disease. Still, risk factor improvements following bariatric surgery did not translate into reduced clinical endpoints when surgery and control groups were compared. It is possible that the small study sample precluded the detection of an actual difference in event rate between the two study groups and larger cohort studies are needed to elucidate the effect of bariatric surgery on clinical outcome.
The main limitation of the present study is its small sample size, which precluded any firm conclusions with respect to cardiovascular outcome. Its strength, on the other hand, is the long-term follow-up of prospectively collected data, which makes it reasonable to conclude that the operative procedure is safe in patients with ischemic heart disease. Another weakness is the nonrandomized design of the study. Despite this, the two groups were quite similar with respect to baseline demographics. Thereby the conclusions with respect to improvements in cardiovascular risk factors, symptoms, and quality of life following surgery seem valid.

In this study most patient were treated with minimal invasive surgery techniques with a known low complication rate (gastric banding or vertical banded gastroplasty). In studies using gastric bypass as surgical method a higher periand postoperative complication rate could be expected.

\section{Conclusion}

Taken together we have provided data that support the safety and feasibility of bariatric surgery in obese patients with IHD. This is encouraging for future-controlled studies prospectively evaluating the long-term effects of bariatric surgery in this patient population. Future trials should aim to explore bariatric surgery in obese patients with IHD and metabolic complications.

\section{References}

[1] J. A. Batsis, A. Romero-Corral, M. L. Collazo-Clavell et al., "Effect of weight loss on predicted cardiovascular risk: change in cardiac risk after bariatric surgery," Obesity, vol. 15, no. 3, pp. 772-784, 2007.

[2] G. D. Alsabrook, H. R. Goodman, and J. W. Alexander, "Gastric bypass for morbidly obese patients with established cardiac disease," Obesity Surgery, vol. 16, no. 10, pp. 12721277, 2006.

[3] D. García-Dorado, A. Castro-Beiras, J. Díez et al., "Cooperative Cardiovascular Disease Research Network (RECAVA)," Revista Espanola de Cardiologia, vol. 61, no. 1, pp. 58-65, 2008.

[4] T. A. Pearson, S. N. Blair, S. R. Daniels et al., "AHA Guidelines for Primary Prevention of Cardiovascular Disease and Stroke: 2002 update: consensus panel guide to comprehensive risk reduction for adult patients without coronary or other atherosclerotic vascular diseases," Circulation, vol. 106, no. 3 , pp. 388-391, 2002.

[5] D. R. Flum, L. Salem, J. A. B. Elrod, E. P. Dellinger, A. Cheadle, and L. Chan, "Early mortality among Medicare beneficiaries undergoing bariatric surgical procedures," Journal of the American Medical Association, vol. 294, no. 15, pp. 1903-1908, 2005.

[6] L. Sjöström, K. Narbro, C. D. Sjöström et al., "Effects of bariatric surgery on mortality in Swedish obese subjects," The New England Journal of Medicine, vol. 357, no. 8, pp. 741-752, 2007.

[7] C. D. Sjöström, "Relationships between changes in body composition and changes in cardiovascular risk factors: the SOS intervention study," Obesity Research, vol. 5, no. 6, pp. 519-530, 1997. 
[8] A. K. Madan, W. Orth, C. A. Ternovits, and D. S. Tichansky, "Metabolic syndrome: yet another co-morbidity gastric bypass helps cure," Surgery for Obesity and Related Diseases, vol. 2, no. 1, pp. 48-51, 2006.

[9] K. G. MacDonald Jr., S. D. Long, M. S. Swanson et al., “The gastric bypass operation reduces the progression and mortality of non-insulin-dependent diabetes mellitus," Journal of Gastrointestinal Surgery, vol. 1, no. 3, pp. 213-220, 1997.

[10] E. J. Whitney, T. L. Ashcom, R. K. Hantman, and J. Heironimus, "Reversibility of fixed atherosclerotic lesions with aggressive risk factor modification," Military Medicine, vol. 156, no. 8, pp. 422-429, 1991.

[11] K. Karason, J. Wikstrand, L. Sjöström, and I. Wendelhag, "Weight loss and progression of early atherosclerosis in the carotid artery: a four-year controlled study of obese subjects," International Journal of Obesity, vol. 23, no. 9, pp. 948-956, 1999.

[12] W. Sturm, A. Tschoner, J. Engl et al., "Effect of bariatric surgery on both functional and structural measures of premature atherosclerosis," European Heart Journal, vol. 30, no. 16, pp. 2038-2043, 2009.

[13] S. Uretsky, F. H. Messerli, S. Bangalore et al., "Obesity paradox in patients with hypertension and coronary artery disease," American Journal of Medicine, vol. 120, no. 10, pp. 863-870, 2007.

[14] H. S. Gurm, D. M. Brennan, J. Booth, J. E. Tcheng, A. M. Lincoff, and E. J. Topol, "Impact of body mass index on outcome after percutaneous coronary intervention (The Obesity Paradox)," American Journal of Cardiology, vol. 90, no. 1, pp. 42-45, 2002.

[15] L. Gruberg, N. Mercado, S. Milo et al., "Impact of body mass index on the outcome of patients with multivessel disease randomized to either coronary artery bypass grafting or stenting in the ARTS trial: the obesity paradox II?" American Journal of Cardiology, vol. 95, no. 4, pp. 439-444, 2005.

[16] L. Gruberg, N. J. Weissman, R. Waksman et al., "The impact of obesity on the short-term and long-term outcomes after percutaneous coronary intervention: the obesity paradox?" Journal of the American College of Cardiology, vol. 39, no. 4, pp. 578-584, 2002.

[17] A. Romero-Corral, V. M. Montori, V. K. Somers et al., "Association of bodyweight with total mortality and with cardiovascular events in coronary artery disease: a systematic review of cohort studies," The Lancet, vol. 368, no. 9536, pp. 666-678, 2006.

[18] E. L. Eisenstein, D. K. McGuire, M. V. Bhapkar et al., "Elevated body mass index and intermediate-term clinical outcomes after acute coronary syndromes," American Journal of Medicine, vol. 118, no. 9, pp. 981-990, 2005.

[19] F. Lopez-Jimenez, S. Bhatia, M. L. Collazo-Clavell, M. G. Sarr, and V. K. Somers, "Safety and efficacy of bariatric surgery in patients with coronary artery disease," Mayo Clinic Proceedings, vol. 80, no. 9, pp. 1157-1162, 2005.

[20] L. Sjöström, A.-K. Lindroos, M. Peltonen et al., "Lifestyle, diabetes, and cardiovascular risk factors 10 years after bariatric surgery," The New England Journal of Medicine, vol. 351, no. 26, pp. 2683-2693, 2004.

[21] J. A. Batsis, M. G. Sarr, M. L. Collazo-Clavell et al., "Cardiovascular risk after bariatric surgery for obesity," American Journal of Cardiology, vol. 102, no. 7, pp. 930-937, 2008. 


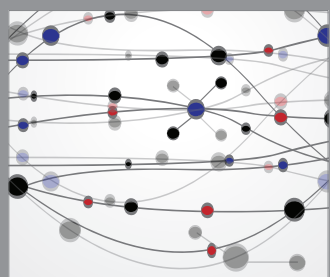

The Scientific World Journal
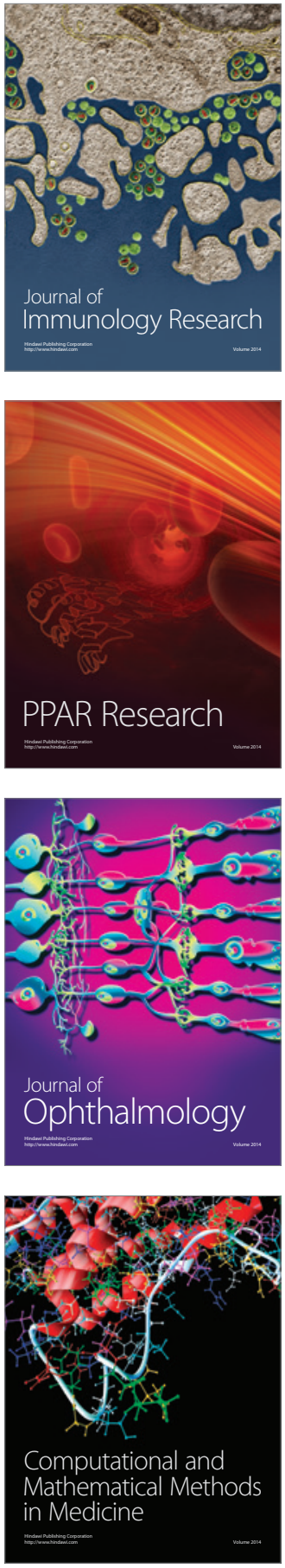

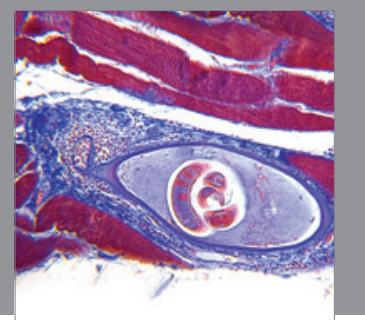

Gastroenterology

Research and Practice
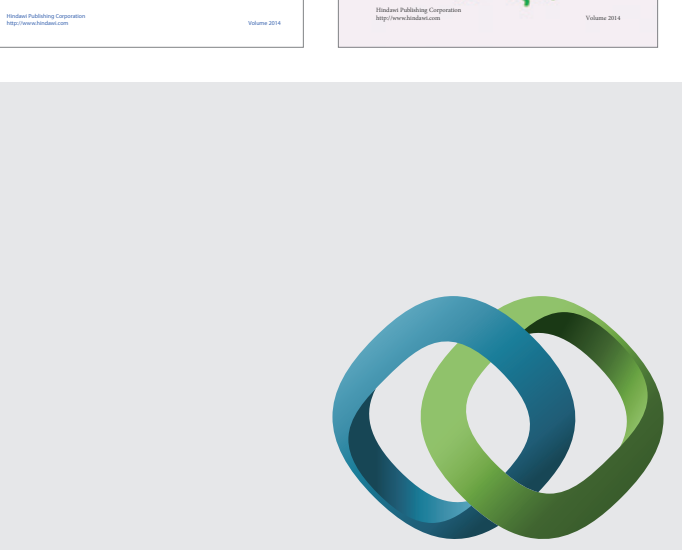

\section{Hindawi}

Submit your manuscripts at

http://www.hindawi.com
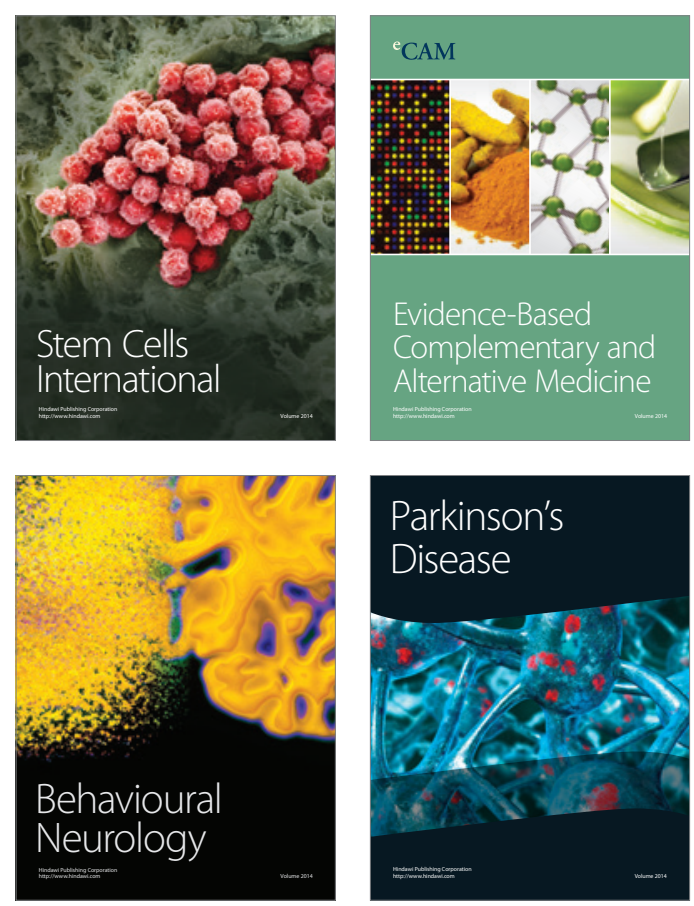

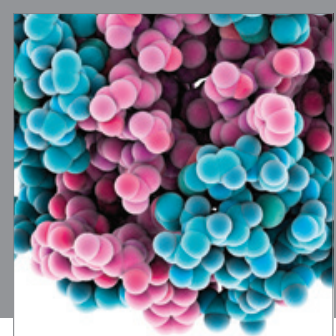

Journal of
Diabetes Research

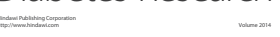

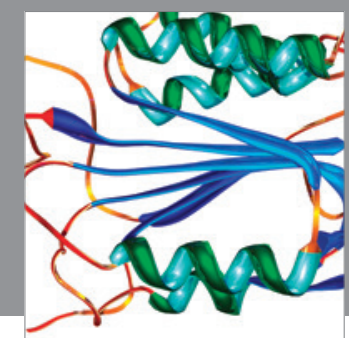

Disease Markers
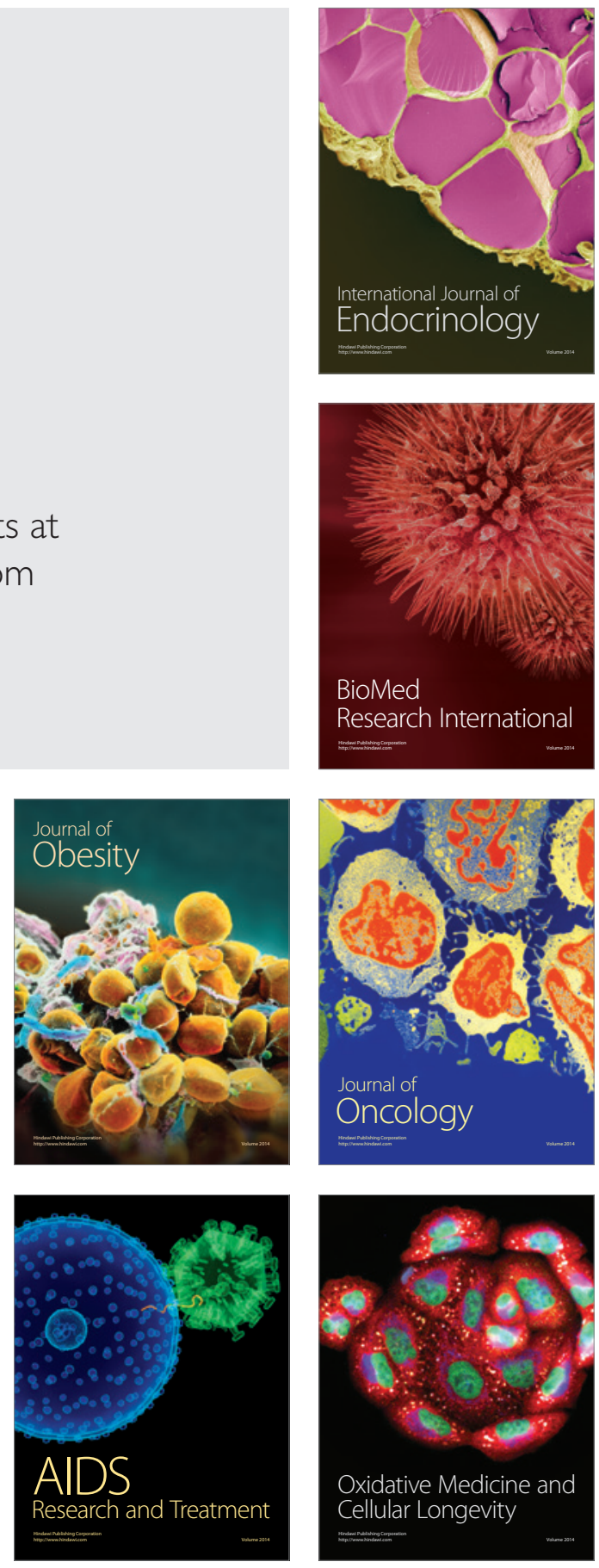